\title{
Explorations into “Elliptic Learning Orbit” Mode in Mobile Phone Learning
}

\author{
Qiufen Yang, Guanqun Liu, Rong Fan \\ Department of Computer Science, Hunan Radio \&TV University, Changsha, 410004, China \\ Email: yqf5569@sohu.com, 14802600 @qq.com, fareu@126.com
}

\begin{abstract}
The development of 3G technology and universality of mobile phones enable farmers in remote rural areas to learn on line at any time and any place. Based on "Application of Information Technology", the paper puts forward the teaching mode of "Elliptic Learning Orbit" which is automatically generated with the two focuses of "online course" and "Mlearning" and suitable for the course teaching. In addition, the teaching mode integrates teachers from CRTVU (Central Television University), Provincial Television University and Municipal Television University to make up a virtual teaching team. They play their own roles, exert their functions, cooperate with each other and complete the teaching task of the course jointly.
\end{abstract}

Keywords-rural university students; application information technology; Elliptic learning orbit; M-learning

\section{INTRODUCTION}

With the continuous development of 3G technology and the gradual universality of mobile phones and other communication equipment, farmers in remote rural areas possess mobile phones and get access to the Internet. Therefore, rural university students can choose to learn what they like at any time and any place. It also provides hardware facility for our teaching as well as convenience for our organization of remote teaching of "Application of Information Technology". The paper puts forward the teaching mode of "Elliptic Learning Orbit" which is automatically generated with the two focuses of "online course" and "M-learning" and suitable for the course teaching. Besides, the teaching mode can optimize teaching effects.

In the new teaching mode, teachers from Central Television University guide the whole virtual course teaching team with 500 members. They serve as the key figures in the team. Provincial and municipal teachers are combined to be called as basic-level teachers in the paper. They assist central teachers to complete the task of providing direct teaching for rural university students. They serve as assistant teachers in the public course teaching and help realize the teaching mode of "Elliptic Learning Orbit" jointly.

\section{II .CHARACTERISTICS OF “APPLICATION OF INFORMATION TECHNOLOGY” FOR RURAL UNIVERSITY STUDENTS}

The plan of "One village, one university student at least" (one-to-one plan) cultivates advanced practical higher vocational talents who "can be retained and used, master technology and management ability". The plain is carried out by China Central Radio \& TV University, depending on the systematic resources in national TV universities and adopting the form of modern open remote education.

Some of these rural university students are Party members, cadre members, leaders and pioneers who guide villagers to gain wealth with technology. They take part in the plan of "One village, one university student at least". The plan cares little about diploma and scores. Instead, it focuses more on one's skills and abilities. Many rural university students are more than 30 years old, poorly educated, greatly different from each other and do not touch books for a long time. Besides, they are mainly village cadres and major breeding farmers. They spend the majority of time on rural chores, breeding and other production activities. Subjectively, they have clear learning purposes. Objectively, they do not have a lot of time for learning.

"Application of Information Technology" is one basic public course in 11 "one-to-one" majors in TV universities. It not only requires that students should master the basic computer knowledge and concepts, but also requires that students should familiarize the basic operations of Office software. It focuses more on students' practical and manipulative abilities. The course adds much inconvenience for rural university students, some of whom even do not have computers, let alone using them. Moreover, the course adopts e-examination form, which undoubtedly intensifies the difficulty for rural university students to learn the course and teachers to teach the course.

The course teaching also demonstrates some themes worth exploring, including how to make use of the current online course resources, changing rural university students' traditional concept of "being unable to do anything without supplementary tools" when they are not skilled in operating computers and even cannot get access to computers, making full use of modern communication resources and cultivating their basic computer operation skills so as to improve students' independent learning ability and realize teaching objectives well.

\section{BRIEF INTRODUCTION TO THE “OVA LEARNING ORBIT” TEACHING MODE}

Based on the specific characteristics of rural university students and "Application of Information Technology" introduced before, with the rapid development of 3G 
technology, the continuous universality of mobile phones and other communication equipment, coupled with the opportunity that farmers in remote rural areas all possess mobile phones and can get access to the Internet, the paper proposes the teaching mode of "Elliptic Learning Orbit" which is automatically generated with the two focuses of "online course" and "M-learning”.

\section{A. Definition of elliptic equation}

First, let's have a look at the definition of elliptic equation (Refer to Fig.1).The orbit of the moving point "M" who distance to two fixed points $F_{1}$ and $F_{2}$ totals up to a constant (larger than $\left|F_{1} F_{2}\right|$ forms an ellipse.

$$
M F_{1}|+| M F_{2} \mid=2 a \quad(2 a>2 c)
$$

The fixed points $F_{1}$ and $F_{2}$ are called elliptic foci. With the changes of the point $\mathrm{M}$, different ellipse groups are generated.

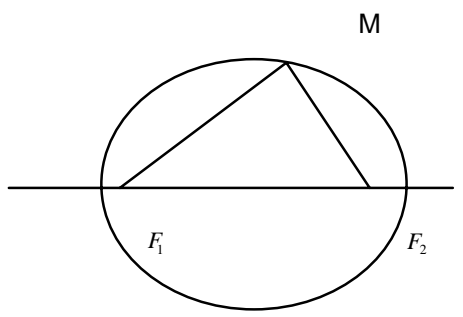

Figure 1. Definition of ellipse

\section{B. "Elliptic learning orbit" learning mode}

In our "Elliptic Learning Orbit" teaching mode, the two foci of the ellipse, $F_{1}$ and $F_{2}$ respectively refer to "online course" and "M-learning".

"Online course" refers to the current online resource in Central TV University, provincial and regional TV universities. "M-learning" refers to learning at any time and any place under the help of mobile communication equipment. The mobile communication equipment can not only effectively demonstrate learning contents but also provide two-way communications between teachers and learners (Aleksander Dye, 2003). In M-learning, mobile phones, PDA and smart phones can all be the terminals. However, for rural university students, they only have mobile phones. In other words, "M-learning" can also be said as "mobile learning". The point " $M$ " refers to the rural university student. Different Learners have their own unique ways to utilize online course resources. The different online learning time and different purposes form different ellipses. Learners obtain different results and various abilities.

C. Advantages of "Elliptic Learning Orbit" teaching mode "Elliptic Learning Orbit” teaching mode has three features.

First of all, "Elliptic Learning Orbit" teaching mode is suitable for rural university students' characteristics. It can solve their contradictions between work and learning so that they can scan the learning contents they need at any time and any place. They can obtain knowledge on bus, when jogging and even working in fields. Moreover, they can even take part in discussions at any time. They can communicate with both teachers and classmates. They do not have to sit in classrooms, at home or in front of computers. It solves the problem about distance among farmers. Distance is no problem any more.

Second, "Elliptic Learning Orbit" teaching mode can solve students' problems in learning in time. When encountering problems, students can ask help from teachers and other learning partners to solve the problems. Besides, they can check their learning effects in time. For example, teachers can assign homework at any time to test learners' learning effects. At the same time, teachers can give learners a feedback about the test results. According to the results, students can make up for their weaknesses and conduct reviews in time so as to better master the contents.

Third, "Elliptic Learning Orbit” teaching mode enables rural university students to choose their own learning contents according to their own weaknesses. They can formulate their own learning schedules so as to maximize individual development and fully demonstrate "independent learning" in remote education.

\section{ROLES OF DIFFERENT-LEVEL TV UNIVERSITY TEACHERS IN THE VIRTUAL TEACHING TEAM}

In terms of teaching management and organization, the teachers in charge of course arrangement in Central TV University are adopted as core figures in the teaching team. The provincial TV universities serve as the backbone. The basic-level TV university teachers serve as participants in the remote virtual teaching team. What is special is that the virtual team is made up of a large number of members, totaling up to 500.

The plan of "One village, one university student at least" is one kind of remote education under the online environment. It centers on learners who carry out learning independently under teachers' guidance. Comparatively speaking, “Application of Information Technology” is quite difficult for rural university students. However, we integrate the huge-scale virtual teaching team made up of 500 teachers from Central TV University, to provincial TV universities to regional TV universities to working stations for the purpose of successfully operating "Elliptic Learning Orbit” teaching mode.

\section{A. Roles of different-level TV university teachers in the team of "Application of Information Technology" teaching team.}

Fig. 2 shows that different-level TV university teachers play different roles due to different labor divisions in "Application of Information Technology". The center of the team is Central TV University teachers who are in charge of the whole team, including the construction of all course resources, such as BBS, two-way video, online Q\&A, discussion zone, announcement board and other remote teaching resources. It also includes teachers' QQ zones, e- 
mails, home pages, BBS, mobile phone numbers, etc. Provincial teachers and regional teachers are all basic-level teachers who are responsible for directly contacting rural university students, BBS problem solving, homework guidance, Web scanning, and sending E-mail. Teachers should try to stimulate learners' initiatives, introduce various information resource services to rural university students, eliminate students' psychological barriers that they cannot solve their problems in the "isolated" rural areas, get rid of students' fear when encountering difficulties and enhance learners' confidence. In this way, students can have the confidence that as long as they are willing to learn, they can learn it well. Besides, students can feel the advancement of remote education, timeliness of lifelong education and substantiality of universal education. In addition, it can stimulate students to improve their own quality and catch up with the times.

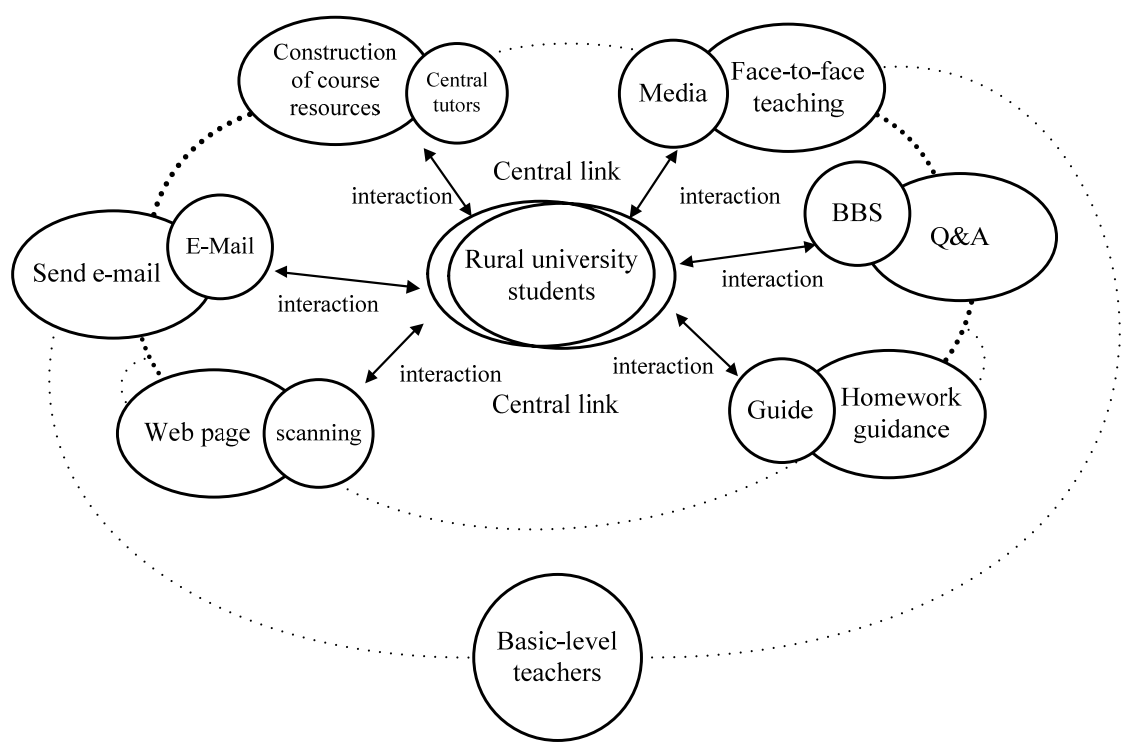

Figure 2. "Elliptic Learning Orbit” virtual team operational mode

\section{B. Responsibilities that teachers should undertake in construction of online courses}

In terms of learning approaches in the course, "item orientation" is adopted as the approach. When making the online course of "Application of Information Technology", the principle of "item orientation" is adopted. The four parts in "Application of Information Technology" are corresponding to four items. Each item is segmented into different sub-items layer by layer.

In terms of the demonstration form of resources, systematic explanation is adopted as the main line. Item orientation is as the guiding line which connects other resources. "Self-learning steps" include preview, class listening, review, test and practical activities. In particular, pertinent to the practice part in "Application of Information Technology", corresponding PPTs are designed. They present the specific operation procedures and teach students step by step. It fully demonstrates the responsibilities of remote education and students' tasks directly. Remote educators are responsible for "guiding learning". Students are responsible for "independent learning".

Rural university students can read the provided text resources and watch the videos and IP resources about the course on WAP websites so that online courses and mobile phones are fully integrated. Besides, the interactions between students and online courses are enhanced.

\section{Basic-level teachers’ responsibilities}

Rural university students are living in remote places or working in fields. It is not easy for them to take part in course tutoring. It requires that course tutors should organize teaching exquisitely and make full use of time so as to strengthen learning effects with half of efforts.

In face-to-face teaching process, we use "task-driven methodology", which actually borrows "anchored" methodology and the teaching idea in "double-host mode" - teacher-and-student interaction in the theory of constructivism learning. To be more specific, tutors segment the teaching objectives into multiple tasks according to Office software. One task corresponds with one objective. In this way, students can learn knowledge while using the software. Therefore, the effects will double. "Task-driven methodology" is applicable to most IT course teaching, such as graphical design, operation of application software, web page making, computer programming, etc. It requires that tutors should design good task chains for rural university students so that they can learn while using and master the basic Office software operational skills.

"Application of Information Technology" is made up of four parts: Windows XP system, Word 2003, Excel 2003 
and PowerPoint 2003. According to the syllabus, pertinent to the four items, teachers formulate different task chains. In Word 2003 learning, teachers can assign the task "How to make one propaganda newspaper which introduces local agricultural products" to guide rural university students to investigate into the task with multiple methods, such as consulting teachers, learning PPT on line, collaboration, independent investigation and so on so that they can come up with corresponding solutions and submit relevant homework or reports. In Excel 2003 learning, teachers can ask learners to classify the different local agricultural products and rank them in orders according to the classification indicator. Classification and summarization are the task chains. Rural university students will feel that the contents are what they need. They can also make use of the data and cases around them. In particular, analysis on cases and presentations penetrate through the functions of classification and summarization, operational steps and matters needing attention so as to enhance learners' comprehension of knowledge. Then, they can consolidate their mastery of knowledge through doing some exercises.

\section{CONCLUSION}

The rapid development of the Internet enables remote education to develop rapidly. The development of 3G technology will bring new development opportunities for the plan of "One village, one university student at least". "Elliptic Learning Orbit" teaching mode is specifically designed for the course "Application of Information Technology" which emphasizes practical operations. It introduces M-learning into the system of cultivating rural university students and provides students with more personalized media resources as well as more humanoriented learning resources in order to provide convenience for students' independent selection. Besides, rural university students can become masters to learning and obtain benefits from life-long education. In fact, the teaching mode can also be spread into other computer course learning.

\section{ACKNOWLEDGMENT}

This research is supported by the 12th five-year plan project in hunan province(No. XJK013BXX006).

\section{REFERENCES}

[1] Lv Yao, A live experience on smartphone learning. Distance Education in China 22 (2010)14-14.

[2] Li Mizhen, Mobile learning and new product application summit forum. Distance Education in China (2013) 97-97.

[3] Lai Zuomei, Performance Comparison of Temporal-Frequency BlockMatching Motion Estimation Algorithm.Computer Engineering and Applications 42(2006)77-79.

[4] Li Zhiguo, An Jinwen, Global motion estimation algorithm based on phase correlation.Computer Measurement \& Control 16(2008)532534.

[5] Chen feng, Application research of digital image processing method for improving signal to noise ratio of seismic section image, Progress in Geophysics18(2003) 758-764.

[6] Fang Baolei, Li Mingzheng, Qiu Yu, Improvement on H.264 UMHexagonS-based motion estimation algorithm. Computer Applications and Software 30(2013)280-282.

[7] Wu Yifeng, Yu Liang, A header bits length estimation algorithm for H.264 based on spatio-termporal correlation. Modern Computer (2013)6-9.

[8] Huang Shuai, Song Guoxin, 2006, Hexagon-based Self-adaptive Search Algorithm Using Successive Elimination. Computer Engineering 32(2006) 212-214.

[9] Han Zhigeng, Wang Jian, Research and improvement of the marking block in the PMVFAST algorithm. Computer Engineering\&Science 28(2006) 70-72.

[10] Liu Changjin, Guo Li, Block matching criterion based on DCT coefficients distribution. Mini-Micro Systems 27(2006) 893-895.

[11] Wei Chang Wong, Chi Chiu Chan, Li Han Chen, Tao Li, Kok Xian Lee, Kam Chew Leong, Polyvinyl alcohol coated photonic crystal optical ber sensor for humidity measurement, Sensors and Actuators B: Chemical, 174 (2012), 563-569.

[12] A.M.S. Muniz, H. Liu, K.E. Lyons, R. Pahwa, W. Liu, F.F. Nobre, J. Nadal, Comparison among probabilistic neural network, support vector machine and logistic regression for evaluating the efect of subthalamic stimulation in Parkinson disease on ground reaction force during gait, Journal of Biomechanics, 43(4) (2010), 720-726.

[13] Nima Mohseni Kiasari, Saeid Soltanian, Bobak Gholamkhass, Peyman Servati, Room temperature ultra-sensitive resistive humidity sensor based on single zinc oxide nanowire, Sensors and Actuators A: Physical, 182 (2012), 101-105. 